\title{
The Epistemic Predicament of a Pseudoscience: Social Constructivism Confronts Freudian Psychoanalysis
}

\begin{abstract}
Social constructivist approaches to science have often been dismissed as inaccurate accounts of scientific knowledge. In this paper, we take the claims of robust social constructivism seriously and attempt to find a theory which does instantiate the epistemic predicament as described by SC. We argue that Freudian psychoanalysis, in virtue of some of its well known epistemic complications and conceptual confusions, provides a perfect illustration of what SC claims is actually going on in science. In other words, the features SC mistakenly ascribes to science in general correctly characterize the epistemic status of Freudian psychoanalysis. This sheds some light on the internal disputes in the field of psychoanalysis, on the sociology of psychoanalytic movement, and on the "war" that has been waged over Freud's legacy with his critics. In addition, our analysis offers an indirect and independent argument against SC as an account of bona fide science, by illustrating what science would look like if it were to function as SC claims it does.
\end{abstract}

Keywords: Social Constructivism, critique of psychoanalysis, pseudoscience, epistemic defects. Sigmund Freud, Frank Cioffi, David Bloor.

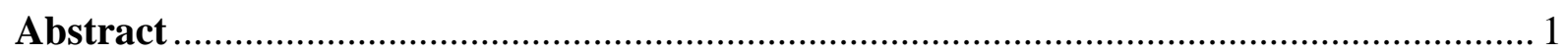

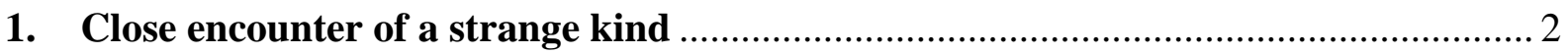

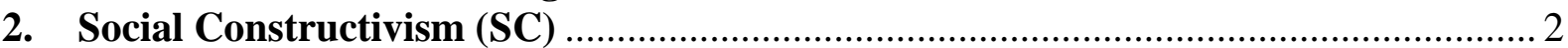

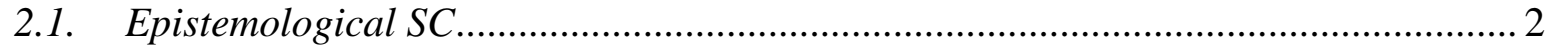

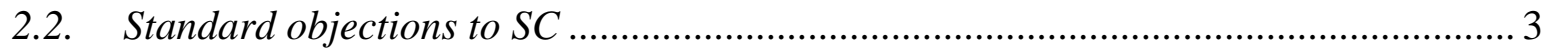

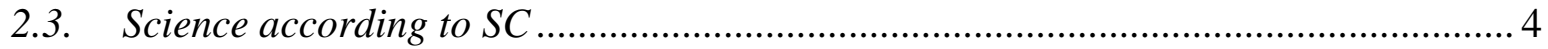

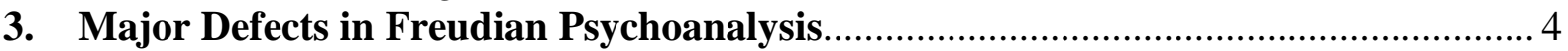

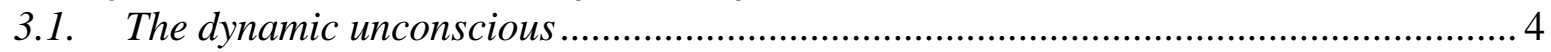

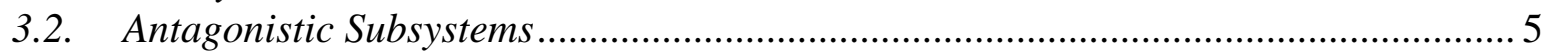

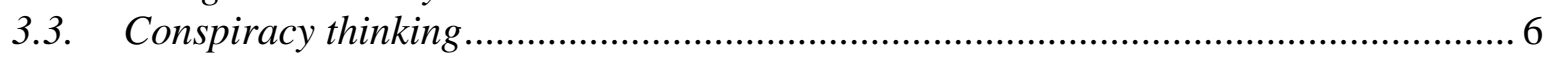

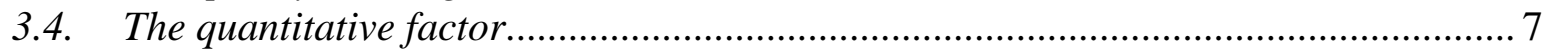

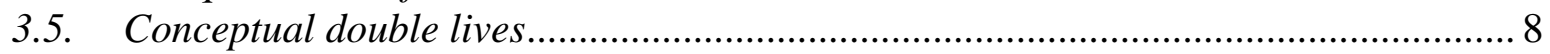

3.6. Inseparability of theory, methodology and practice ............................................. 8

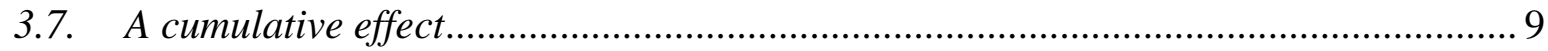

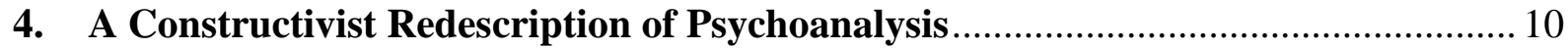

4.1. SC and Freudian psychoanalysis: no constraints on evidence …........................... 10

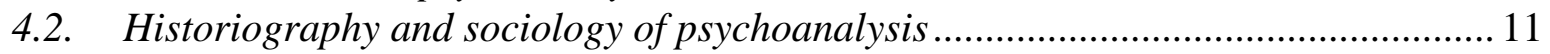

4.3. The Construction of meaning and the archaeological metaphor .............................. 11

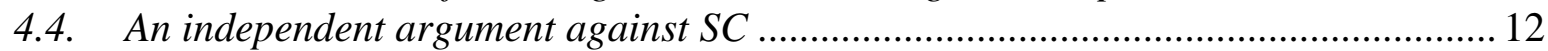

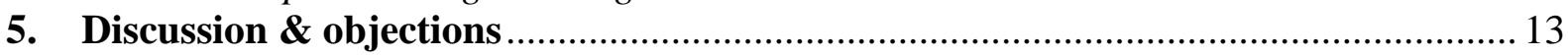

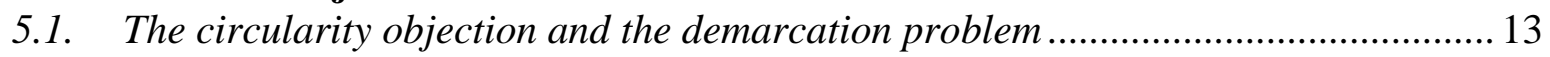

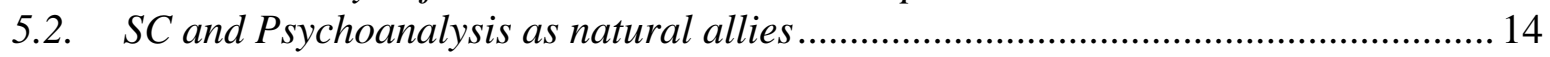

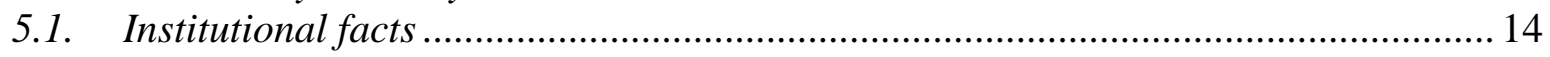




\section{Close encounter of a strange kind}

In recent controversies over psychoanalysis, which for their unremitting vehemence became known as the "Freud Wars", the scientific status of Freud's legacy has been hotly disputed. Almost simultaneously, another war was being waged over the status of science itself. In the socalled "Science Wars", social constructivist approaches to science were put against more traditional epistemic approaches to science and scientific rationality. Our aim in this paper is to show that classical Freudian psychoanalysis, in virtue of some of its well known epistemic deficiencies, methodological complications and conceptual confusions, provides an intriguing illustration of what science would look like if it were to function as SC claims it does.

The analysis developed here yields an independent and indirect argument against SC as an account of bona fide science, and reveals a fascinating connection between the two "wars". (for previous encounters between SC and psychoanalysis, see Moore 1999; Gillett 1998; BorchJacobsen and Shamdasani 2008). In particular, we show how the framework of SC sheds some light on the internal disputes in the field of psychoanalysis, on the sociology of psychoanalytic movement, and on the "war" that has been waged over Freud's legacy with his critics. Our own approach partly builds on earlier work on the reconstruction of psychoanalytic hermeneutics as a system of unintended institutional facts (Buekens and Boudry 2011, in press; Buekens 2006), based on Searle's theory of institutional facts (1995) .

\section{Social Constructivism (SC)}

\subsection{Epistemological SC}

Social Constructivism (SC) comes in many flavours, and the term covers a broad variety of interrelated theories. This ranges from commonsense views about how artefacts and social institutions are constructed by human agents, to controversial and radical theories about the status of knowledge, science and the nature of reality. Noretta Koertge holds that terms like "social construction" or "constructivism", "while they signal a certain sympathy towards nouveau ideas, have no precise referent" (Koertge 1996, p. 269; compare with Haslanger 2003). ${ }^{1}$ In this article, we will be concerned with a robust version of SC as applied to scientific knowledge ${ }^{2}$. We will not be concerned with normative and evaluative connotations often associated with constructivist approaches (Hacking 1999, p. 6), as these will not be directly relevant for our epistemological perspective.

In traditional accounts of knowledge, it is taken for granted that " $[\mathrm{u}]$ nder the appropriate circumstances, our exposure to the evidence alone is capable of explaining why we believe what we believe" (Boghossian 2006, p. 22). By contrast, robust SC assumes, as Harry Collins put it in his seminal article, that "the natural world in no way constrains what is believed to be" (Collins 1981a, p. 54) and that "the natural world has a small or non-existent role in the construction of scientific knowledge" (Collins 1981b, p. 3). According to SC, the natural world has no significant

\footnotetext{
${ }^{1}$ Haslanger (2003, p. 301) remarks that "the variety of different uses of the term has made it increasingly difficult to determine what claim authors are using it to assert or deny".

${ }^{2}$ Rather than exposing particular entities as socially constructed against a background of natural facts, we see SC as being involved in the revision of central concepts like knowledge, truth and reality, coined "elevator terms" by Hacking (1999, p. 21).
} 
bearing on theory choice in science. In explaining the beliefs of scientists, the proponent of SC will not appeal to their exposure to the relevant evidence, but rather to non-epistemic factors, such as sociological context, ideological influences and material conditions. This approach is embodied in the so-called 'Strong Programme' for the sociology of scientific knowledge, as developed by David Bloor. More specifically, Bloor's methodological "symmetry postulate" for the explanation of scientific beliefs states the following:

[The sociology of scientific knowledge] would be symmetrical in its style of explanation. The same types of cause would explain say, true and false beliefs. (Bloor 1991, p. 7)

The symmetry postulate ... enjoins us to seek the same kind of causes for both true and false, [and] rational and irrational, beliefs .... (Bloor 1991, p. 175) ${ }^{3}$

This downplaying of epistemic considerations has important consequences for the question of theory change and paradigm shifts in science, as was pointed out by Golinski:

Given sufficient creativity and resourcefulness on behalf of its defenders, any existing paradigm could be maintained indefinitely. [...] Why, then, should a paradigm ever change? (2005, p. 25)

Following Bloor, Golinski argues that, in order to explain a paradigm shifts, we should pay attention to the "social characteristics of the paradigm community and the balance of forces within it". As the natural world does not constrain theory choice or paradigm shifts, a scientific consensus merely reflects the contingent social and cultural preferences of the scientific community. Bloor does acknowledge that there "will be other types of causes apart from social ones" (Bloor 1991, p. 7), but presumably, the presence of such non-social causes does not account for the difference between true vs. false or rational vs. irrational beliefs. After all, the symmetry postulate invites us to look for the same type of causes in all cases.

It is often noted that the revisionist proposals of robust SC entail bold or prima facie absurd claims, and one might wonder whether any self-proclaimed proponent of SC sincerely endorses them (see also footnote 3). Are the critics of SC attacking a straw man? According to Kukla, the situation is more complicated, as the field of SC abounds in what he terms "reverse switcheroos":

$[\mathrm{Y}]$ ou put forth a strong version of the hypothesis, and when it gets into trouble, you retreat to a weaker version, pretending that it was the weaker thesis that you had in mind all along. (Kukla 2000, p. x)

Thus, while many proponents of SC try to disown such radical interpretations when pressed on the issue, their writings often do imply them. In any case, as we will see, the more robust version of SC turns out to be most interesting from an epistemological perspective.

\subsection{Standard objections to SC}

Excellent philosophical critiques of robust SC have been formulated by Kitcher (1998), Koertge (2000) and Boghossian (2006). The standard problems associated with SC can be briefly rehearsed. First, critics claim that SC is incapable of explaining scientific success. If the natural world does not significantly affect the course of scientific development, how are we to explain

\footnotetext{
${ }^{3}$ Some adherents of the Strong Programme claim that the 'symmetry postulate' is a purely methodological precept that does not say anything about the actual causes of scientific belief, but this seems incoherent. If the natural world plays an important role in the construction of scientific knowledge after all, why would a good sociologist of science decide to ignore this role in practice?
} 
the successful applications of scientific knowledge? Second, SC is haunted by the spectre of Epimenedes, the ancient Cretan who proclaimed that "all Cretans are liars". If epistemic reasons never explain belief in a particular theory, what about the epistemic warrant for SC itself? The theory seems to be self-defeating ${ }^{4}$. Third, critics of SC maintain that the theory rests on implausible generalizations and misconceptions of certain post-positivist developments in philosophy of science (Koertge 2000). For example, the well-known problem of theory-ladenness of observation (TLO) is often misconstrued as lending support to the SC claim that nature does not in any way put constraints on theory formation. However, TLO does not apply uniformly and with equal force in every scientific context, and it is premature to conclude that it is fatal to the epistemic warrant of scientific claims. By applying TLO indiscriminately in every context, a subtle and valuable insight in philosophy of science has been lost. ${ }^{5}$ The underdetermination of a theory by evidence (Quine 1953; Duhem 1954) is another thesis that is often confused with the stronger SC thesis of the radical contingency of scientific knowledge. Whereas W.V. Quine made a purely logical point about the possibility of preserving a hypothesis in the face of conflicting evidence, leaving room for pragmatic considerations in theory choice (elegance, explanatory power, etc.), defenders of SC think that underdetermination makes science completely impervious to evidence (see Hacking 1999, pp. 71-75). ${ }^{6}$

\subsection{Science according to $S C$}

In this paper, we will approach SC from a different perspective and pose the following question: supposing that scientific inquiry and practice were to function as SC claims they do, what exactly would they look like? Can we find a theory which does actually instantiate the epistemic predicament as described by SC? In the following sections, we show that Freudian psychoanalysis, in virtue of well known and extensively documented defects in its epistemological foundations, methodology and conceptual apparatus, indeed exemplifies the general characteristics that SC (mistakenly) ascribes to serious science and scientific practice. Our analysis yields a new and independent strategy for challenging SC as a viable account of bona fide science, by offering a reductio of the SC program. In section 3 we briefly review a number of major conceptual and methodological flaws in Freudian psychoanalysis that have been extensively discussed elsewhere (Esterson 1993; Macmillan 1997; Cioffi 1998; Crews 1986). In section 4 we show how SC provides an excellent account of how psychoanalytic theories are developed and accepted. Philosophical worries about circularity in our argument will be addressed in section 5.1.

\section{Major Defects in Freudian Psychoanalysis}

\subsection{The dynamic unconscious}

\footnotetext{
${ }^{4}$ David Bloor has tried to solve this problem by including the postulate of symmetry in his Strong Programme, stating that the principles of the Strong Programme should in principle be applicable to itself (Bloor 1991, p. 7). As it stands, however, Bloor has merely restated the problem, without discharging the objection of self-refutation.

${ }^{5}$ Once again, the danger of a vicious self-reference lurks, as Hacking observed: "To see all observations as equally loaded with theory is in itself to practice theory-laden observation, that is, observation loaded with a theory derived from Hanson the philosopher." (Hacking 1999, p. 200) In any case, scientists do not always have to decide in favour of one theory, but can also - and often do - suspend judgement, awaiting further empirical or conceptual developments (Slezak 1994, p. 281).

${ }^{6}$ Moreover, SC exaggerates the factors of individual epistemic distortions in scientific practice for example confirmation bias, prejudice, selective use of evidence or ideological bias. These distortions do occur in scientific practice, as in any other human activity, but in many cases the effects are sooner or later neutralized, because science is an eminently self-correcting social activity.
} 
Freudian psychoanalysis consists of both a complex dynamic psychology, a method for investigating the human mind and a framework for interpreting human behaviour (in this paper we are not concerned with the effects of psychoanalytic therapy). Psychoanalytic doctrine revolves around the notion of the dynamic unconscious, an imperceptible realm of the human mind full of repressed mental contents, mostly sexual phantasies and desires stemming from early childhood.

The explananda of psychoanalytic interpretations cover a wide range of mental phenomena and their products, including neurotic symptoms, irrational thoughts and behaviour, dream contents, slips of the tongue, works of art, social phenomena like religions, etc.. ${ }^{7}$ The structure of a psychoanalytic interpretation typically takes the form " $\mathrm{X}$ is/counts as $\mathrm{Y}$ ", where the $\mathrm{Y}$-position is occupied by a psychoanalytic concept, and the X-position by an empirical description of observational source material, to which the psychoanalytic concept is assigned. According to the Freudian psychoanalyst, human thoughts and actions display certain anomalies, quirks and inconsistencies which betray the working of unconscious motives and fantasies. These psychological phenomena are supposed to reveal, through a sometimes complex chain of associations, hidden unconscious processes and meanings. Typical instances of psychoanalytic interpretations include: "your compulsive behaviour is in fact an enactment of perverse childhood fantasies", "the stranger in the dream represents your father" or "your emotional insecurity is a manifestation of infantile castration anxiety".

Although we deliberately restrict our analysis to classical Freudian psychoanalysis, it should be noted that the divergent psychoanalytic schools that followed Freud's seminal theory have typically retained much of the problematic methodology and epistemology instituted by Freud: the existence of the psychodynamic unconscious, the notion of repression, the method of free association and symbolic interpretation as the gateway to the unconscious, etc. To the extent that these psychoanalytic schools have relied on the same defective aspects of the theory, our arguments apply with equal force (Macmillan 1997; Cioffi 1998).

\subsection{Antagonistic Subsystems}

According to Freudian psychoanalysis, the human mind is the playground of a constant struggle between different mental subsystems. On the one hand, Freud often describes these mental systems as possessing intentional content, characterizing them in terms of personal-level concepts borrowed from folk psychology. In his early work, Freud analyzes the purposeful interaction between the unconscious and a mental entity called the censoring mechanism, which attempts to keep repressed mental contents from entering consciousness by means of distortion and disguise. This dynamic framework of antagonistic subsystems was later developed into the tripartite division of Ego, Super-Ego and Id. On the other hand, however, Freud also describes these different mental subsystems and their mutual interactions in purely mechanical terms, for example as being in the business of discharging and distributing a form of mental energy called libido. This tension between personal-level psychology and an impersonal libidinal economy has persisted throughout psychoanalytic literature (Gardner 2000).

Freud developed a complex set of technical concepts to describe dynamical interactions between different mental subsystems. For example, the concept of "negation" describes the transformation of an unconscious wish into a negative form (its denial) upon entering

\footnotetext{
${ }^{7}$ In Buekens and Boudry (in press) we defend that, in virtue of its pseudohermeneutical character, psychoanalysis is capable of understanding virtually every human phenomenon.
} 
consciousness; "substitution" denotes the replacement of mental content by a substitute through a chain of unconscious association, in which the libido of the first content is transferred to the second, a process of displacement called "cathexis". "Condensation" denotes the bringing together of libidinal energy in one link connecting two associative chains. "Inversion" and "repression" similarly represent mental mechanisms for transforming mental contents through an invisible libidinal economy.

The dynamic and open-ended character of these concepts inflates the possibility of drawing analytical inferences from observable source material (i.e. the explanandum in a psychoanalytic interpretation) to unconscious mental states and processes. In addition, Freud's psychology allows a single element in the empirical source material to have multiple unconscious determinants, a phenomenon often referred to as "overdetermination". These conceptual resources enable the psychoanalyst to make creative use of different sorts of symbolic associations, linguistic connections, double-entendres and homonyms, creating multiple layers of psychoanalytic interpretation. Importantly, what critics perceived as methodological extravagance was for the Freudians themselves inextricably connected with the very nature of the object of inquiry: we are dealing with a dynamic and intentional unconscious after all, which is in constant struggle with the mechanism of censorship, and which seeks ingenious and deceitful ways to provide an outlet for amassed libidinal energy.

Consider, for example, Freud's use of the concept of "inversion". Frank Cioffi convincingly argued that, although Freud theorized that neurosis develops when perverse desires remain unsatisfied, he did not recognize that patients who overtly indulged in their perverse desires but were neurotic nonetheless, constituted a refutation of his theory (Cioffi 1998, pp. 119-121). In the case of patients who suffered from neurosis without displaying overtly perverse behaviour, Freud explained the symptoms as an outlet for libidinal energy amassed in response to repressed perversities. In the case of overtly perverse neurotic patients, Freud maintained that the symptoms expressed a repressed aversion against their indulging in perversities, and constituted a case of "inversion".

Another example of typical psychoanalytic reasoning is the way apparent falsifications of the Oedipus complex were handled. For Freud, the affectionate behaviour of little boys towards their mother was a manifestation of incestuous desire. On the other hand, if a boy showed affection towards the father and was cold or hostile towards the mother, as in the famous case of Little Hans, Freud explained the behaviour as a reaction formation against the actual incestuous desires, which he thought were partially repressed (Freud 1955a; Van Rillaer 1980, pp. 141-155). Thus, the concepts of inversion and reaction formation allowed Freud to account for virtually every observation.

\subsection{Conspiracy thinking}

The Freudian unconscious is an entity that actively resists interpretation, and that will always try to deceive us in unexpected and cunning ways (Gellner 1985). ${ }^{8}$ Thus, when Freud was unable to find traces of a pathological complex or unconscious desire to account for a patient's behaviour, he was undeterred and treated this as a token of unconscious resistance. The more the material offered by a patient resisted interpretation, the more it counted in favour of the theory. This

\footnotetext{
${ }^{8}$ Or more precisely, in both simple and far-fetched ways. The degree of complexity in psychoanalytic interpretations varies greatly, from very straightforward symbols for genitals on the basis of superficial visual similarities, to intricate, multi-layered and multi-lingual analyses.
} 
characteristic pattern of reasoning in psychoanalysis bears a striking resemblance to conspiracy theorizing (Farrell 1996). For example, consistent with his account of the unconscious, Freud believed that his patients (and his critics) harboured a secret and unconscious wish to see his theories and interpretations proven wrong, and so never to see their own unconscious desires exposed. For instance, one of Freud's patients dreamt that she had to spend her holidays with her despised mother-in-law. This seemed to belie Freud's claim that every dream is an unconscious wish-fulfilment, but within the framework of psychoanalytic thinking it could be turned into a confirmation of the theory. As Freud himself explained,

The dream showed that I was wrong. Thus it was her wish that I might be wrong, and her dream showed that wish fulfilled. [italics in original] (Freud 1953a, p. 151)

Freud argued that "these dreams appear regularly in the course of my treatments when a patient is in a state of resistance to me" and he predicted that the same would happen to his readers (Freud 1953a, pp. 157-158). ${ }^{9}$ Indeed, Freud and his followers became infamous for explaining away criticism from their opponents as tokens of unconscious resistance to the theory, thus further attesting to the truth of psychoanalysis:

They [the critics] are therefore bound to call up the same resistance in him as in our patients; and that resistance finds it easy to disguise itself as an intellectual rejection and to bring up arguments like those which we ward off in our patients by means of the fundamental rule of psycho-analysis. (Freud 1957, p. 39)

What is important for our purposes is that such moves are not merely immunizing gambits which can be neatly disentangled from the theory, but are instead perfectly legitimate, explanatory moves within the psychoanalytic framework, and instantly recognizable as genuine psychoanalytic interpretations (Boudry and Braeckman 2010). This pattern of reasoning, which bears a striking resemblance to conspiracy thinking, is pervasive throughout psychoanalytic literature, and it follows directly from the characterization of the unconscious as an intentional and deceitful mental entity.

\subsection{The quantitative factor}

Freud treated a patient's explicit denial of his hypotheses - for example in his use of the concept of penis envy - as yet further confirmation of his claims, but that didn't mean that he was prepared to accept cases where patients readily accepted his interpretations as refuting his theory. Indeed, if the patient's dreams seemed to confirm Freud's notions, they could be explained as an example of "compliance towards the analyst", and thus again be relegated to unconscious motives (Freud 1961, p. 117) Thus, neither the denial or the (belated) acceptance of an interpretation posed a problem from the perspective of Freudian theory.

The difference between both forms of behaviour could be explained by the analyst as the result of unobservable variations in the strength of unconscious resistance on the one hand and the intensity of libidinal energy on the other hand. This "quantitative factor" in the patient's mental economy had the effect of forestalling the falsification of what initially looked like testable predictions. As Freud himself made clear in a remarkably candid passage, it could always be invoked post factum to account for the unexpected presence or absence of any given symptom:

\footnotetext{
${ }^{9}$ The quotation continues: "Indeed, it is to be expected that the same thing will happen to some of the readers of the present book: they will be quite ready to have one of their wishes frustrated in a dream if only their wish that I may be wrong can be fulfilled."
} 
We cannot measure the amount of libido essential to produce pathological effects. We can only postulate it after the effects of the illness have manifested themselves. (Freud 1924, p. 119)

\subsection{Conceptual double lives}

Another important feature of Freudian psychoanalysis, which further contributes to its epistemic predicament, is that its concepts lead what may be called a "double life" (Cioffi 1998, p. 118): sometimes they seem to be semantically-rich and clearly-delineated, but on other occasions they are inflated so as to become almost indefinite and meaningless. This conceptual double life makes central psychoanalytic concepts virtually immune to refutation. Cioffi (1998, p. 15) mentions Freud's "disingenuous alternation" in the scope of the libido-concept, in which he switches between an explicitly sexual libido on the one hand and a general kind of love and affection on the other hand. ${ }^{10}$

As pointed out earlier, many concepts in Freudian psychoanalysis (e.g. repression, projection, wish-fulfilment) alternate between personal-level psychology and blind libidinal economy, a form of equivocation that makes psychoanalytic interpretations particularly ambiguous and elusive (Gardner 2000). Esterson (1993, p. 230) has concluded that the functions of the central concepts in Freud's ego-psychology (Ich, Über-Ich, Es) “are so imprecisely delineated that they can be employed in almost arbitrary fashion to provide support for virtually any theoretical formulation." Elsewhere (Buekens and Boudry in press) we have argued that the extension of many psychoanalytic terms is not fixed until applied in interpretations, which goes some way to explaining their open and indeterminate meaning (Borch-Jacobsen and Shamdasani 2006).

\subsection{Inseparability of theory, methodology and practice}

A number of critics of psychoanalysis (Grünbaum 1984, 2008; Eagle 1988; 1996, 2002) have insisted on a clear distinction between the theory-as-such and the tendency of its advocates to use immunizing gambits and other methodological tricks in the face of falsifying material. These authors maintain that the theoretical problems we reviewed above have nothing to do with psychoanalysis properly speaking, but should be laid at the door of individual analysts.

In this paper, however, we follow critics like Cioffi (1998), Crews (1986) and Macmillan (1997), who have meticulously demonstrated that, in practice, it is all but impossible to pinpoint where the orthodox version of the theory ends and where immunizing strategies and methodological obfuscations begin (Boudry and Braeckman 2010). This is because what Grünbaum and Erwin designate as "dubious" methodological practices and immunizing tactic emerge directly from theory-internal epistemic properties. As Cioffi wrote:

(W)e have no canonical statement of the theory: no agreement on what constitutes modifications of the theory rather than post hoc elucidations of it. [...] What we have in Freudian theory is a combination of epistemically ambiguous utterances with methodologically suspect practices. (Cioffi 1998, p. 300)

\footnotetext{
${ }^{10}$ This semantically double life of concepts like 'libido' fulfilled two conflicting demands: on the one hand, only the narrow, carnal interpretation could explain why fathers threatened their sons with penile amputation and why libidinal drives were so inadmissible for our moral sensibilities that they had to be repressed; on the other hand, only the wider interpretation allowed Freud to maintain that beneath the surface of each and every symptom the libidinal factor is lurking.
} 
The way in which the concept of resistance has been put to use by Freud and his acolytes, for example, has been rightly dismissed by critics as a specimen of heads-I-win-tails-you-lose reasoning. Nevertheless, it proves difficult to disentangle such fallacious reasoning from psychoanalytic theory itself, because it is effectively supported by the way the unconscious is conceptualized in Freudian theory. If Freud's model of the human mind is correct, and if the unconscious really is some sort of trickster in disguise, then indeed it becomes natural to label counter-arguments and criticisms as manifestations of unconscious resistance to psychoanalytic 'truths' and 'interpretations'.

\subsection{A cumulative effect}

The remarkably versatile and multi-directional methodology of Freudian psychoanalysis (Timpanaro 1976; Macmillan 1997; Cioffi 1998), which has long been noted by its critics, is the natural outcome of dividing the mind into intentional and antagonistic substructures. As we have seen, Freud's particular dynamic conception of the human mind creates an abundance of inferential possibilities when applied in hermeneutical practice, enabling the analyst to turn any psychological phenomenon into the symptomatic outcome of a hidden psychodynamic conflict. In addition, the conceptual equivocations in the theory render Freud's hermeneutic machinery even more versatile. ${ }^{11}$ As Frederick Crews wrote:

Each posited subset of 'the unconscious' permits another strand of contrary motivation to be added to the already tangled explanatory skein, leaving us, if we are sufficiently gullible, so impressed by the psychoanalytic interpreter's diagnostic acumen that we think we are witnessing elegant and validated feats of deduction instead of being told a self-serving detective story in which the mystery itself [...] is an artefact of question-begging manoeuvres.

(Crews 2006, p. 56)

The cumulative effect of these methodological and conceptual problems is that, if the psychoanalytic unconscious exists, it is deprived of any capacity to put epistemic constraints on theoretical claims and psychoanalytic interpretations. Indeed, any guarantee for interpretive congruency in Freudian psychoanalysis is frustrated by the methodological flexibility and conceptual deficiencies inherent within the theory (Van Rillaer 1980, pp. 87-92; Esterson 1993, p. 242; Macmillan 1997). This was the verdict reached by Malcolm Macmillan in his Freud Evaluated:

the so-called discoveries are dependent upon methods of enquiry and interpretation so defective that even practitioners trained in their use are unable to reach vaguely congruent conclusions about such things as the interpretation of a dream or symptom [...] (Macmillan 1997, p. 516)

Indeed, the internal feuds and factions characterizing post-Freudian psychoanalysis bear witness to the epistemological problems described by critics as Macmillan and Cioffi (Borch-Jacobsen and Shamdasani 2006, 2008). Already in 1962, the psychoanalyst Judd Marmor observed (with understandable disquietude) that, by means of the psychoanalytic method, confirmations could

\footnotetext{
11 The therapeutic methods of free association and transference analysis, although demonstrably unavailing for probing another person's mind (Grünbaum 1984) and based on placebo effects (Jopling 2008), are not discussed here as one of the central methodological pitfalls of psychoanalysis, because these methods are not employed in psychoanalytic interpretation of human phenomena like works of art, literary texts or religion, and thus do not constitute the central epistemic problem of psychoanalysis.
} 
be found as easily for Freud's Oedipus complex, as for Adler's inferiority complex, or for Lacan's symbolic Father, or for Jung's anima and persona:

dependent on the view of the analysts the patients of each school generate precisely those data that support the theories and interpretations of their analysts. (Marmor 1962, p. 289)

Returning to the main issue, we will now show that these findings resonate with the SC tenet that "what is believed to be" (Collins 1981a, p. 54) is in no way constrained by "nature" (in this case, what is going on in our minds).

\section{A Constructivist Redescription of Psychoanalysis}

\subsection{SC and Freudian psychoanalysis: no constraints on evidence}

Our central claim is that Freudian psychoanalysis perfectly illustrates the epistemological predicament described by proponents of SC. Indeed, the critique of psychoanalysis presented in the previous sections resonates with the "debunking project" that is central to the program of SC. As Boghossian aptly noted:

a social construction claim is interesting only insofar as it purports to expose construction where none had been suspected, where something constitutively social had come to masquerade as natural. (Boghossian 2006, p. 18)

This is exactly what critics of Freudian psychoanalysis have been engaged in all along: exposing as "constructions" what Freudian theorists presented as genuine natural facts out there, waiting to be discovered. ${ }^{12}$ The received critical view of Freudian theory could be rephrased as follows: what psychoanalysts present as 'insights' and 'findings' are merely artefacts of the theory itself and of its deficient methodology; only those who have already embraced Freudian theory 'see' the described psychoanalytic phenomena (e.g. the phallic meaning of a dream symbol; the child's erotic pleasure in thumb sucking).

The epistemic predicament of Freudian psychoanalysis can now be redescribed within the framework of SC. Take the critical observation that, in Freudian hermeneutics, any guarantee for interpretive congruency is frustrated by the methodological flexibility and conceptual versatility of the system. As Harry Collins would have it, "what is believed to be" in psychoanalytic hermeneutics is "in no way constrained" (1981a, p. 54) by what is actually going on in our minds. This perfectly illustrates two key tenets of SC, viz. that evidential considerations play an insignificant role in theoretical developments, and that the resolution of theoretical debates and conflicts in psychoanalysis is not driven by epistemic considerations.

The critical observation that psychoanalysts always succeed - sometimes with considerable ingenuity - in moulding seemingly adverse evidence into accordance with their theory, illustrates another tenet of SC: the ability to preserve the theory in the face of recalcitrant material. As Golinski put it, "given sufficient creativity and resourcefulness on behalf of its defenders, the existing paradigm could be maintained indefinitely" (Golinski 2005, p. 25). Most philosophers of science would agree that this is a rather implausible claim when applied to bona fide science, but in the case of psychoanalysis we claim that the description is perfectly accurate. Fully in line with Judd Marmor's observation, critics of psychoanalysis have often noted that there is no rational

\footnotetext{
12 After all, to be meaningful and coherent, Freudian theory has to presuppose that there is an independent mental reality and that the analytic method yields knowledge about it, this in spite of later attempts at a hermeneutical (Ricœur 1970; Habermas and Shapiro 1981) or constructivist reconstruction of psychoanalysis (Spence 1982; Schafer 1992; Moore 1999).
} 
method to resolve the persistent disputes between the followers of Sigmund Freud, Otto Rank, Alfred Adler, Jacques Lacan, Daniel Winnicott, Anna Freud, Melanie Klein and many others. For example, when his disciple Otto Rank introduced the concept of birth trauma as a pre-oedipal source of neurosis (a Freudian heresy), Freud could only reply that he was unable to confirm the remnants of such a trauma in his clinical work, and he urged a reinterpretation of the material in terms of oedipal desires. Both schools have since then continued to find 'confirmations' for their own theoretical framework, and have failed to 'see' the mental phenomena described by their adversaries (Cioffi 1998, pp. 17-19).

\subsection{Historiography and sociology of psychoanalysis}

For the historiographer of psychoanalysis, David Bloor's "symmetry postulate" seems an appropriate methodological tool. Since the theoretical choice for Oedipus complex, death wish, inferiority complex or birth trauma does not depend on the nature of empirical evidence, one must resort to deeply non-epistemic factors to explain theoretical disputes, developments, and schisms in the history of psychoanalysis (Borch-Jacobsen and Shamdasani 2006). As the Strong Programme recommends, the historiographer of sociologist or psychoanalysis should not be concerned with the "truth" of such or such psychoanalytic doctrine, and in all cases he should look for the "same kind of causes", viz. ideological background, social networks, personal animosity, and cultural context.

To give just one example, in the second half of the $20^{\text {th }}$ century the doctrine of universal penis enyy in women was progressively abandoned in many psychoanalytic schools. It is quite implausible that this theoretical change was driven by evidential considerations, for Freudians theorists had 'confirmed' the doctrine countless times in the past and touted it as one of the cornerstones of analytic theory (Cioffi 1998, pp. 27-28). Moreover, the method of investigation remained the same, so what could account for this theoretical development? Instead of looking for epistemic reasons, historians of psychiatry and psychoanalysis would be better advised to investigate the changing social and cultural sensibilities of the time, which began to regard the concept as patriarchal and misogynist. The development of the psychoanalytic concepts of breast envy (Melanie Klein) and womb and vagina eny (Karen Horney) to compensate for this "phallocentrism" on Freud's part must be seen in the same light (Sayers 1987). Indeed, $19^{\text {th }}$ century preconceptions about female submissiveness and inferiority constitute a good candidate for explaining the genesis of the concept of penis envy in the first place. This focus on sociological and ideological causes is precisely what sociologists of scientific knowledge like Bloor would recommend. The idea that the concept of universal penis envy was gaining acceptance in Freud's time because "Nature had spoken" and psychoanalysts had paid heed to Her is quite implausible in light of a critical assessment of Freud's theory and methodology. As David Bloor would have it, "What function does truth, or talk of truth, play in all this? It is difficult to see that much would be lost by its absence" (Bloor 1991, p. 40). In the absence of epistemic constraints on theory change, the explanatory vacuum is filled in with various sociological, ideological and psychological factors.

\subsection{The Construction of meaning and the archaeological metaphor}

It is interesting to note that Freud himself acknowledged that the work of the analyst closely resembles the practice of (re)construction. About his analysis of the Wolf Man, Freud wrote:

All I mean to say is this: scenes, like this one in my present patient's case, which date from such an early period and exhibit such a content, and which further lay claim to such an extraordinary significance for the history of the case, are as a rule not reproduced as 
recollections, but have to be divined - constructed - gradually and laboriously from an aggregate of indications. (Freud 1955b, p. 51)

Freud also compared the psychoanalyst to the archaeologist, carefully excavating the buried remnants of the past and uncovering layer after layer of unconscious meaning (Freud 1953b, 1955a). But of course, the context of psychoanalytic inquiry does not resemble the direct accessibility of archaeological excavations at all, as Freud could only tenuously infer the existence of alleged unconscious phenomena on the basis of certain cues (dreams, associations, patterns of behaviour) (Moore 1999). In psychoanalytic therapy, the archaeology metaphor reinforces the misconception that the psychoanalyst merely brings to the surface that which was present all along in the patient's mind. ${ }^{13}$ Freud used other realism-inducing metaphors to describe the inquiries of the analyst. For example, he likened the manifest dream content to a "rebus" or "picture puzzle", in which symbols have to be deciphered to reveal hidden meanings (Freud 1953a, pp. 277-278). These powerful metaphors conveyed the image of an inquiry into an objective mental reality out there, and they have paved the way for a misinterpretation of Freudian social constructions as natural, empirically-detectable facts.

\subsection{An independent argument against SC}

The first part of our central argument is that the framework of SC offers an accurate account of the epistemic predicament of psychoanalysis, in particular the classical Freudian version. We will now argue that that SC's applicability to psychoanalysis yields that it must embody a bad account of how bona fide science works.

To secure this conclusion, we need to show that a successful description of Freudian psychoanalysis in terms of a social-constructivist account succeeds in virtue of methodological and conceptual problems that are not manifest, or at least not to the same extent present in bona fide science. There is some circumstantial evidence for this claim: many of the features we discussed are widely recognized as distinctively psychoanalytic, even by Freud's contemporaries (BorchJacobsen and Shamdasani 2006), and they were criticised on independent factual and theoretical grounds (Esterson 1993; Macmillan 1997; Cioffi 1998). Indeed, for many scientists and philosophers, they served as the basis to question the theory's scientific credentials (Derksen 1993; Cioffi 1998; Popper 2002).

The central question remains, however, what it takes for a theory to exemplify the epistemic situation as described by SC. The proponent of SC can retort that our argument is superfluous: "Even if so-called bona fide science doesn't exhibit the specific problems you correctly identified in psychoanalysis, it is no less socially constructed". Our opponent may maintain that the viability of a constructivist redescription of Freudian psychoanalysis is not due to the characteristic problems we mentioned, but due to general features that are also manifest in bona fide science. In other words, the specific problems we discussed are superfluous, and bona fide science is just as much "socially constructed".

However, this would entail that the various theoretical complications and loopholes of Freudian psychoanalysis, which have fascinated critics and defenders alike, are epistemically gratuitous. The proponent of SC is then committed to denying that these characteristic problems are responsible for what critics have condemned as the epistemic vacuousness of Freudian psychoanalysis, and

\footnotetext{
${ }^{13}$ In that sense, the hypothesis of a dynamic unconscious full of forbidden wishes and desires, combined with the concepts of repression and denial, creates favorable psychological conditions for the creation of false insight and successful suggestion (Jopling 2008).
} 
this is quite implausible. First, it is simply incoherent to claim that the conceptual and methodological flaws have no epistemic consequences, i.e. are epistemically inert. We have documented in detail that their cumulative effect consists of reducing epistemic constraints on hermeneutic practice and theory formation, to produce spurious evidence about an object that is actually an artefact of the theory (the dynamic unconscious), and to distract attention from this very process. ${ }^{14}$ Even defenders of psychoanalysis have occasionally acknowledged that these specific problems compromise the theory's epistemic status and its aspiration to be recognized as a genuine science (Eagle 1993). Second, there are good reasons to assume that in other respects they bindered the success of the theory, since they undeniably compromised its credibility in the eyes of countless scientists and philosophers.

Note that our dialectical position is not committed to the implausible claim that the methodological and conceptual problems that plague Freudian psychoanalysis are entirely absent from bona fide science. Imre Lakatos maintained that every scientific theory builds a "protective belt" (Lakatos and Musgrave 1970) of auxiliary hypotheses around its core claims. Likewise, the theory-ladenness of observation is a genuine problem that affects bona fide science as well. But this is a far cry from the stronger picture outlined by SC. Every theory can withstand a certain amount of anomalies using face-saving auxiliaries, but that does not mean that they are all on equal footing. The strength and imperviousness of the protective belt around a core theory is a matter of degree, not of absolute difference. One does not need to be a naive falsificationist to recognize that, in bona fide science at least, a sufficient number of empirical anomalies may indeed threaten a theory, especially if far-fetched modifications are in order to get the theory in accordance with reality. In Freudian psychoanalysis, by contrast, the particular methodological problems and conceptual resources we discussed ensure that no amount of empirical observations can seriously endanger central psychoanalytic propositions. No matter what nature says, psychoanalysts always hear her speaking in the same voice. Because of its specific epistemic predicament, Freudian psychoanalysis, in contrast with bona fide science, exemplifies the picture of science SC defends and promotes. In that sense, we have uncovered an example of what science would look like if it were to function as SC claims it does.

\section{Discussion \& objections}

\subsection{The circularity objection and the demarcation problem}

"Your argument begs the question," the critic may retort. "On the one hand you claim that Freudian psychoanalysis is a pseudoscience, because it displays the features described by SC. On the other hand, you hold that SC is a bad account of science because it correctly describes a pseudoscience (i.e. Freudian psychoanalysis). This is a circular argument."

This objection allows us to clarify the overall structure of our argument. First, our empirical argument against SC as an account of scientific practice is independent from traditional conceptual and philosophical objections (they were briefly rehearsed at the beginning of this article). Secondly, we do not reject Freudian psychoanalysis just because it fits the SC framework. We do not propose our analysis as a new demarcation criterion, and we do not think that our framework is capable of capturing all the features that characterize pseudosciences. Third, it may well be that some of the methodological and conceptual problems we have discussed figure in proposed solutions to the demarcation problem (Derksen 1993), but it does not follow that we thereby also endorse that demarcation criterion, nor that our argument depends on the rejection of

\footnotetext{
${ }^{14}$ See for example Freud's explicitly empiricist and objectivist rhetoric (Buekens and Boudry in press)
} 
Freudian psychoanalysis as pseudoscience under that supposed demarcation criterion. The only relevant premises in our argument are (i) the presence of these characteristics and defects ${ }^{15}$ in Freudian psychoanalysis, and (ii) their cumulative effect on the epistemic status of the theory. It may well be possible - although this was not a line we intended to take - to turn the case of Freudian psychoanalysis against SC on the presupposition that there is a correct demarcation criterion according to which psychoanalysis should be dismissed as a pseudoscience. However, this will not impress the defender of SC, since the possibility of a viable demarcation criterion separating science from pseudoscience is precisely what is problematic from the point of view of SC. In this article we tried to give an independent argument against SC, not an argument that simply presupposes the very characterization of science SC objects to.

\section{2. $\quad S C$ and Psychoanalysis as natural allies}

It is interesting to note that some contemporary psychoanalysts have themselves embraced some version of SC (Spence 1982; Stern 1992; Schafer 1992; Moore 1999). In this constructivist school, the empirical ambitions of Freud are largely abandoned, and it is argued that "narrative truth" or "interpretive construction" is everything a psychological theory (or indeed any theory) can offer. Eagle (2003) has conclusively argued that, by renouncing any claim at empirical insight, this postmodern version of psychoanalysis inevitably leads to relativism. However, one might wonder why SC has attracted the attention of so many psychoanalysts. It seems plausible that constructivist readings of psychoanalysis help neutralizing scientific and philosophical objections to Freud's theory by extrapolating the epistemological problems from which psychoanalysis suffers to science in general. In that very specific sense, psychoanalysts find a natural ally in constructivists, some of whom have been found to openly embrace relativism (Bloor 2007).

\subsection{Institutional facts}

In Buekens \& Boudry (in press) we develop an account of psychoanalysis as a system of "institutional facts" along the lines of John Searle's theory of social institutions (Searle 1995; Lagerspetz 2006) and propose this analysis as the best explanation of what really happens in the hermeneutic practice of psychoanalysis. The upshot of that analysis is that psychoanalysis is based on a confusion between natural facts and institutional facts: what Freud thought of as descriptions of natural facts are, to a large extent, declaratives that create and, when accepted by others, sustain institutional facts. In contrast with global SC, the reconstruction in Buekens \& Boudry (in press) assumes a firm distinction between natural facts, which exist independently of human intentionality, and institutional facts. This differs from the implausible anti-realist credo of SC that all scientific facts are socially constructed. The argument in Buekens \& Boudry (in press) resonates with the conclusion in this paper that Freudian theories and interpretations are "social constructions" rather than verifiable natural facts about the vicissitudes of the human mind.

\subsection{Conclusion}

SC approaches to science have often been dismissed as inaccurate accounts of scientific knowledge. Our aim in this paper was to take the claims of radical SC seriously and to find out whether we can uncover theories which do instantiate the epistemic predicament as described by SC. As we have shown, (Freudian) psychoanalysis fits the bill, in virtue of its well-known conceptual problems, its peculiar epistemic structure and its methodological flexibility. The

\footnotetext{
15 The fact that we talk about 'defects' may seem tendentious. However, our argument does not depend on this terminology but stands in its own right. In any case, with this choice of term, we are not suggesting that we endorse a demarcation criterion on the basis of these characteristics.
} 
combination of what psychoanalysis pretends to be (i.e. a science), and the way the theory really functions (i.e. a system that produces arbitrary constructions), makes a redescription in the framework of SC particularly apt. By showing in some detail what it takes for a theory to 'create' its own object, our analysis yields an independent argument against SC as a global account of science.

\section{Bibliography}

Bloor, D. (1991). Knowledge and Social Imagery. Chicago: University Of Chicago Press.

----- (2007). Epistemic grace: Antirelativism as theology in disguise. Common Knowledge, 13(2-3), 250.

Boghossian, P. A. (2006). Fear of Knowledge: Against Relativism and Constructivism. Oxford: Oxford University Press.

Borch-Jacobsen, M. and S. Shamdasani (2006). Le dossier Freud: enquête sur l'bistoire de la psychanalyse. Paris: Empêcheurs de penser en rond.

------ (2008). Interprefactions: Freud's legendary science. History of the buman sciences, 21(3), 1-25.

Boudry, M. and J. Braeckman (2010). Immunizing strategies \& epistemic defense mechanisms. Philosophia. doi:10.1007/s11406-010-9254-9

Buekens, F. (2006). Freuds Vergissing. De illusies van de psychoanalyse. Leuven: Van Halewyck.

Buekens, F. and M. Boudry (2011). Unintended Institutional Facts. On the Structure of Psychoanalytic Hermeneutics. In K. François, B. Löwe, T. Müller and B. van Kerkhove (Eds.), Foundations of the Formal Sciences VII. London: King's College Publications.

----- (in press). Freudian Hermeneutics and Unintended Institutional Facts. Philosophy of the Social Sciences.

Cioffi, F. (1998). Freud and the question of pseudoscience. Chicago: Open Court.

Collins, H. M. (1981a). Son of Seven Sexes: The Social Destruction of a Physical Phenomenon. Social Studies of Science, 11(1), 33-62.

----- (1981b). Stages in the empirical program of relativism - Introduction. Social Studies of Science, 11(1), 3-10.

Crews, F. C. (1986). Skeptical engagements. Oxford: Oxford University Press.

----- (2006). Follies of the Wise: Dissenting Essays. Emeryville, CA: Shoemaker \& Hoard.

Derksen, A. A. (1993). The seven sins of pseudo-science. Journal for General Philosophy of Science, 24(1), 17-42.

Duhem, P. M. M. (1954). The aim and structure of physical theory. Princeton (N.J.): Princeton university press.

Eagle, M. (1993). The Dynamics of Theory Change in Psychoanalysis. In J. Earman, A. Janis, N. Rescher and G. Massey (Eds.), Philosophical Problems of the Internal and External Worlds: Essays on the Philosophy of Adolf Grünbaum (pp. 373-408). Pittsburgh: University of Pittsburgh Press.

Eagle, M. N. (1988). Skeptical Engagements - Crews, F. (book review). Contemporary Psychology, 33(5), 404-405.

----- (2003). The Postmodern Turn in Psychoanalysis: A Critique. Psychoanalytic Psychology, 20(3), 411-424.

Erwin, E. (1996). A Final Accounting: Philosophical and Empirical Issues in Freudian Psychology. Cambridge, MA: MIT Press. 
----- (2002). The Freud Encyclopedia: Theory, Therapy, and Culture. New York: Routledge.

Esterson, A. (1993). Seductive Mirage: An Exploration of the Work of Sigmund Freud. Chicago: Open Court.

Farrell, J. (1996). Freud's paranoid quest: Psychoanalysis and modern suspicion. London: New York University Press.

Freud, S. (1924). Collected papers. Vol. 2. London: The Hogarth Press Ltd and The Institute of Psycho-Analysis.

----- (1953a). Standard edition. Vol. 4, (1900) The interpretation of dreams (first part). London: Hogarth Press.

----- (1953b). Standard edition. Vol. 7, (1901-1905) : A case of hysteria ; Three essays on sexuality; and other works. London: Hogarth Press.

----- (1955a). Standard edition. Vol. 10, Two case histories: 'Little Hans' and the 'Rat man'. London: Hogarth Press.

------ (1955b). Standard edition. Vol. 17, (1917-1919) : An infantile neurosis, and other works. London: Hogarth Press.

----- (1957). Standard edition. Vol. 11, (1910) : Five lectures on psycho-analysis, Leonardo da Vinci, and other works. London: Hogarth Press.

----- (1961). Standard edition. Vol. 19, (1923-1925): The ego and the id, and other works. London: Hogarth Press.

Gardner, S. (2000). Psychoanalysis and the personal/sub-personal distinction. Philosophical Explorations: An International Journal for the Philosophy of Mind and Action, 3(1), 96 - 119.

Gellner, E. (1985). The Psychoanalytic Movement: The Cunning of Unreason. London: Paladin.

Gillett, E. (1998). Relativism and the Social-constructivist Paradigm. Philosophy, Psychiatry, and Psychology, 5(1), 37-48.

Golinski, J. (2005). Making natural knowledge: Constructivism and the history of science. Chicago: University Of Chicago Press.

Grünbaum, A. (1984). The foundations of psychoanalysis: a philosophical critique. Berkeley: University of California Press.

----- (2008). Popper's Fundamental Misdiagnosis of the Scientific Defects of Freudian Psychoanalysis and of their Bearing on the Theory of Demarcation. Psychoanalytic Psychology, 25(4), 574-589.

Habermas, J. and J. J. Shapiro (1981). Knowledge and human interests. London: Heinemann.

Hacking, I. (1999). The social construction of what? Harvard: Harvard University Press.

Haslanger, S. (2003). Social Construction: The 'Debunking’ Project. In F. Schmitt (Ed.), Socializing Metaphysics (pp. 301-325). Lanham, MD: Rowman \& Littlefield.

Jopling, D. A. (2008). Talking Cures and Placebo Effects. Oxford: Oxford University Press.

Kitcher, P. (1998). A Plea for Science Studies. In N. Koertge (Ed.), A House Built on Sand: exposing postmodern myths about science (pp. 32-56). Oxford/New York: Oxford University Press.

Koertge, N. (1996). Wrestling with the Social Constructor. In P. Gross, N. Levitt and M. Lewis (Eds.), The flight from science and reason (pp. 266-273). Baltimore Johns Hopkins University Press.

---- (2000). 'New age' philosophies of science: constructivism, feminism and postmodernism. The British Journal for the Philosophy of Science, 51(4), 667-683.

Kukla, A. (2000). Social constructivism and the philosophy of science. New York: Routledge.

Lagerspetz, E. (2006). Institutional facts, performativity and false beliefs. Cognitive Systems Research, 7(2-3), 298-306.

Lakatos, I. and A. Musgrave (1970). Criticism and the Growth of Knowledge. Cambridge: Cambridge University Press.

Macmillan, M. (1997). Freud Evaluated: The Completed Arc. Cambridge, MA: MIT Press. 
Marmor, J. (1962). Psychoanalytic Therapy as an Educational Process. In J. Messerman (Ed.), Psychoanalytic Education Science Series (Vol. 5, pp. 286-299). New York: Orune \& Stratton.

Moore, R. (1999). The Creation of Reality in Psychoanalysis: A View of the Contributions of Donald Spence, Roy Schafer, Robert Stolorow, Irwin Z. Hoffman, and Beyond. Hillsdale, NJ: Analytic Press.

Popper, K. R. (2002). Conjectures and refutations: The growth of scientific knowledge. London: Routledge.

Quine, W. V. O. (1953). From a logical point of view. Cambridge, Mass.: Harvard University Press.

Ricœur, P. (1970). Freud and philosophy : an essay on interpretation. New Haven: Yale University Press.

Sayers, J. (1987). Melanie Klein, psychoanalysis, and feminism. Feminist Review, 25, 23-37.

Schafer, R. (1992). Retelling a Life: Narration and Dialogue in Psychoanalysis. New York: Basic Books.

Searle, J. R. (1995). The Construction of Social Reality. New York: Free Press.

Slezak, P. (1994). Sociology of scientific knowledge and scientific education: Part I. Science \& Education, 3(3), $265-294$.

Spence, D. P. (1982). Narrative truth and historical truth : meaning and interpretation in psychoanalysis. New York / London: Norton.

Stern, D. (1992). Commentary on constructivism in clinical psychoanalysis. Psychoanalytic Dialogues, 2, 331-363.

Timpanaro, S. (1976). The Freudian slip : psychoanalysis and textual criticism. London: Verso.

Van Rillaer, J. (1980). Les illusions de la psychanalyse. Bruxelles: Mardaga. 